December 10, 1980<smiles>CCCCC</smiles>

\title{
EVALUATION OF ULTRASONIC SIGNALS FROM DIFFUSION AND EUTECTIC BOND INTERFACES
}

Charles M. Brown

Research and Development NONDESTRUCTIVE TESTING GROUP
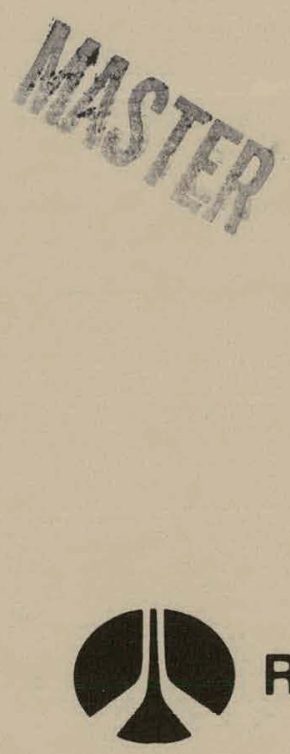
Rockwell International

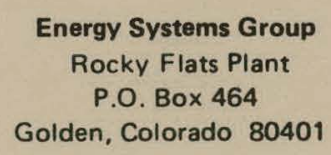




\section{DISCLAIMER}

This report was prepared as an account of work sponsored by an agency of the United States Government. Neither the United States Government nor any agency Thereof, nor any of their employees, makes any warranty, express or implied, or assumes any legal liability or responsibility for the accuracy, completeness, or usefulness of any information, apparatus, product, or process disclosed, or represents that its use would not infringe privately owned rights. Reference herein to any specific commercial product, process, or service by trade name, trademark, manufacturer, or otherwise does not necessarily constitute or imply its endorsement, recommendation, or favoring by the United States Government or any agency thereof. The views and opinions of authors expressed herein do not necessarily state or reflect those of the United States Government or any agency thereof. 


\section{DISCLAIMER}

Portions of this document may be illegible in electronic image products. Images are produced from the best available original document. 
This report was prepared as an account of work sponsored by an agency of the United States Government. Neither the United States Government nor any agency thereof, nor any of their cmployees, makes any warranty, express or implied, or assumes any legal liability or responsibility for the accuracy, completeness, or usefulness of any information, apparatus, product, or process disclosed, or represents that its use would not infringe privately owned rights. Reference herein tu any specific com mercial product, process, or service by trade name, trademark, manufacturer, or otherwise, does not necessarily constitutc or imply its endorsement, recommendation, or favoring by the United States Government or any agency thereof. The views and opinions of authors expressed herein do not necessarily state or reflect those of the United States Government or any agency thereof.

\footnotetext{
Printed in the United States of America Available from the

National Technical Information Service

U.S. Department of Commerce Springfield, Virginia 22161

$\begin{array}{cc}\text { Page Range } & \text { Domestic Price* } \\ 001-025 & \$ 5.00 \\ 026-050 & 6.00 \\ 051-075 & 7.00 \\ 076-100 & 8.00 \\ \text { *All microfiche are priced at } \$ 3.50 \\ \text { Prices Subject to Change Without Notice }\end{array}$
}


Printed

December 10, 1980
RFP-2964

U-38 ENGINEERING \& EQUIPMENT

TIC-4500 (Rev. 68)

\section{EVALUATION OF ULTRASONIC SIGNALS FROM DIFFUSION AND EUTECTIC BOND INTERFACES}

Charles M. Brown

- Research and Development NONDESTRUCTIVE TESTING GROUP

Prepared under Contract DE-AC04-76DPO3533

for the

Albuquerque Operations Office

U.S. Department of Energy 


\section{A C K N O W L E D G M E N T}

The author wishes to acknowledge the work of Ben Cross and Dick Adams who developed and coordinated the initial diffusion-bonded test sample study. 


\section{CONTENTS}

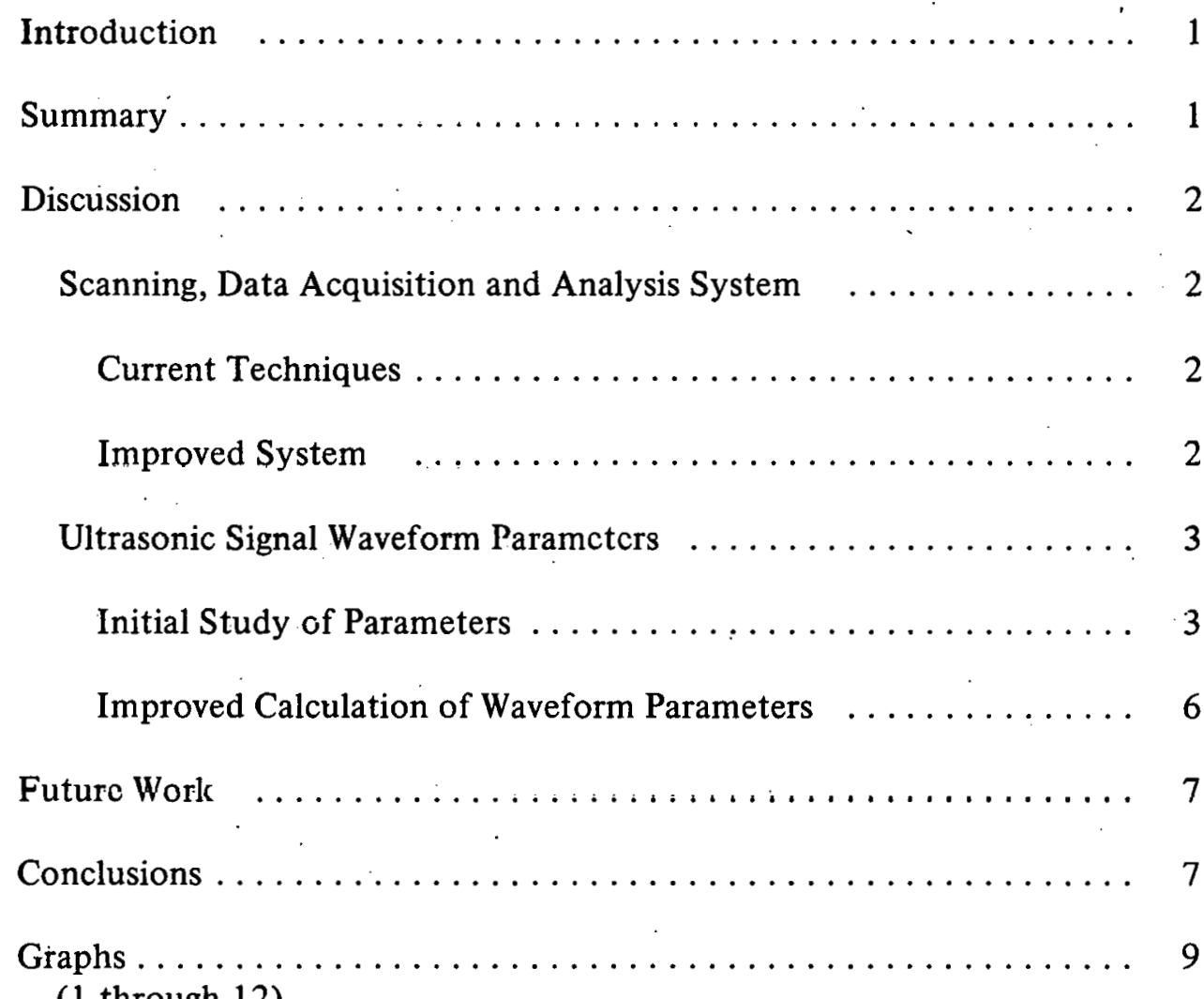

(1 through 12) 
RFP-2964 


\title{
EVALUATION OF ULTRASONIC SIGNALS FROM DIFFUSION 'AND EUTECTIC BOND INTERFACES
}

\author{
Charles M. Brown
}

\begin{abstract}
A research program is in progress at Rocky Flats to determine correlations between ultrasonic signal content and diffusion or eutectic bond joint condition, and to develop a computercontrolled scanning, data acquisition and analysis system which utilizes these correlations and waveform analysis techniques. The initial efforts to determine effective ultrasonic waveform parameters to characterize the strength of bond interfaces is complete. A development version of a computercontrolled, automated scanning and data acquisition system is in operation.
\end{abstract}

\section{INTRODUCTION}

A research program currently in progress at Rocky Flats is directed toward improving signal and data processing technology used to ultrasonically evaluate touch braze integrity. The objectives of this program are to determine correlations between ultrasonic signal content and bond joint condition and to develop a scanning, data acquisition and analysis system utilizing advanced waveform anialysis techniques.

Current evaluation of bond joints is performed by recording and plotting the maximum amplitude of ultrasonic pulse reflection from the acoustic impedance mismatch at the braze joint while scanning the part. To improve the ability to analyze ultrasonic wave form information from NDT tests, a computer-controlled, automated scanning and data acquisition system has been designed which performs online capture, storage, and analysis of waveform signals by the control computer.

The initial efforts to determine effective ultrasonic waveform parameters to characterize the strength of diffusion and eutectic bond interfaces is complete. Further studies to develop additional waveform parameters to better distinguish bond strength and to apply these parameters to actual NDT tests have hegun.

\section{SUMMARY}

A development version of a computer-controlled, automated scanning and data acquisition system is in operation. The new system uses a minicomputer to control the NDT test scanner, data acquisition, data storage, test output, and operator communication through a real time resident task which is part of the computer operating system. The system can sample the entire ultrasonic pulse waveform at each scan point, recording the data on computer storage devices or processing it in real time as the scan proceeds.

A study to determine correlations between ultrasonic response and actual bond condition was performed by fabricating and analyzing a set of diffusion-bonded test coupons. The initial effort to determine if a correlation existed was performed by Adaptronics, Inc. (McLean, Virginia) using Adaptive Learning Network (ALN) analysis. Evaluation of Adaptronics' results showed their models were not ready for production use. The results were suspect in part because one of the initial methods of parameter calculation introduced inconsistant data into the analysis. Waveform parameter calculation methods from the initial study were improved and incorporated into a second evaluation of the original data. The recalculated parameters show improved separation and grouping of data necessary for bond classification.

Further studies to develop additional waveform parameters designed to better differentiate diffusion and eutectic bond strength are planned. In addition, future experiments may be performed to provide a larger data base and to develop additional signal processing and feature extraction variables. Final work will apply the techniques developed from these studies to production NDT tests of touch braze bonds. 


\section{DISCUSSION}

\section{Scanning, Data Acquisition and Analysis System}

\section{Current Techniques}

Current evaluation of eutectic bond joints is performed by examining the maximum amplitude of ultrasonic pulse reflection from the acoustic impedance mismatch at the braze joint. The impedance mismatch at a noribonded area results in a larger reflected pulse than the mismatch at a bonded area. The amplitude of the ultrasonic reflection from the bond interface is recorded as the part is scanned. The resulting information is displayed for evaluation on a strip chart recorder or an X-Y plotter; then the information is contourplotted by computer.

Figure 1 shows the system currently in use for scanning test parts and acquiring amplitude data from the bond interface. An automated motor controller moves the scanner in a continuous operation while an electronic analog output representing the peak amplitude of the reflected ultrasonic signal is plotted on a chart recorder or sampled at set intervals. Sampled data are recorded as digital information on cassette tape to be processed later by computer. Output from the current system differentiates noticeable changes in acoustic impedance mismatch at the bond interface. However, the system does not lend itself to more refined analysis of reflected ultrasonic information which requires sampling the entire waveform signal.

\section{Improved System}

To improve the ability to analyze ultrasonic waveform information from ND'T tests, a computercontrolled, automated scanning and data acquisition system has been designed and an initial version completed. The new system performs online capture, storage, and analysis of waveform signals by the control computer. The system allows improved characterization of waveform signals and permits the development of parameters which better represent the nature of the test specimen bond.

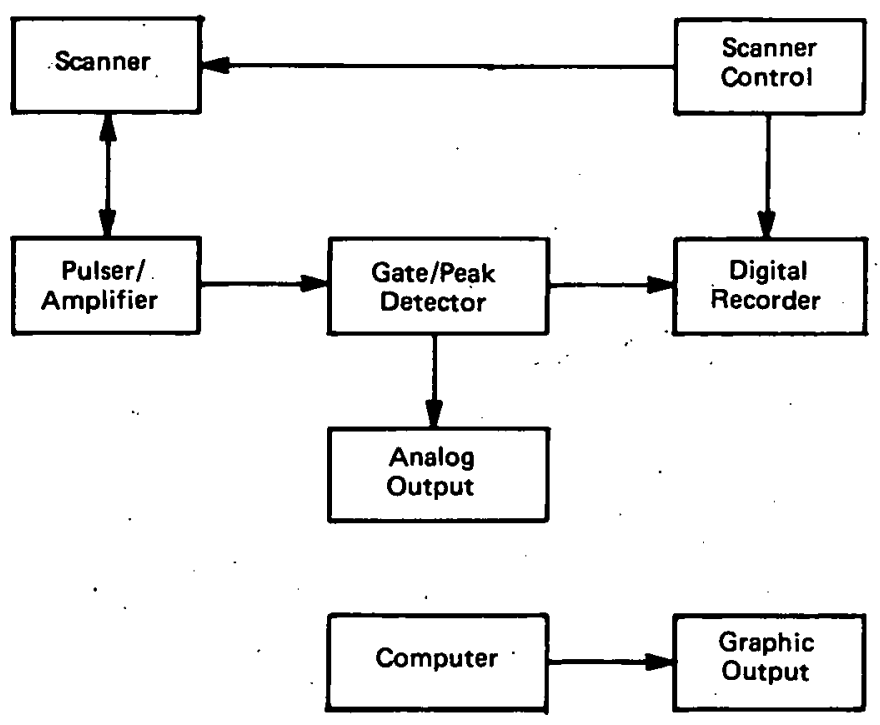

FIGURE 1. Current NDT Test System

FIGURE 2. Improved NDT Test System

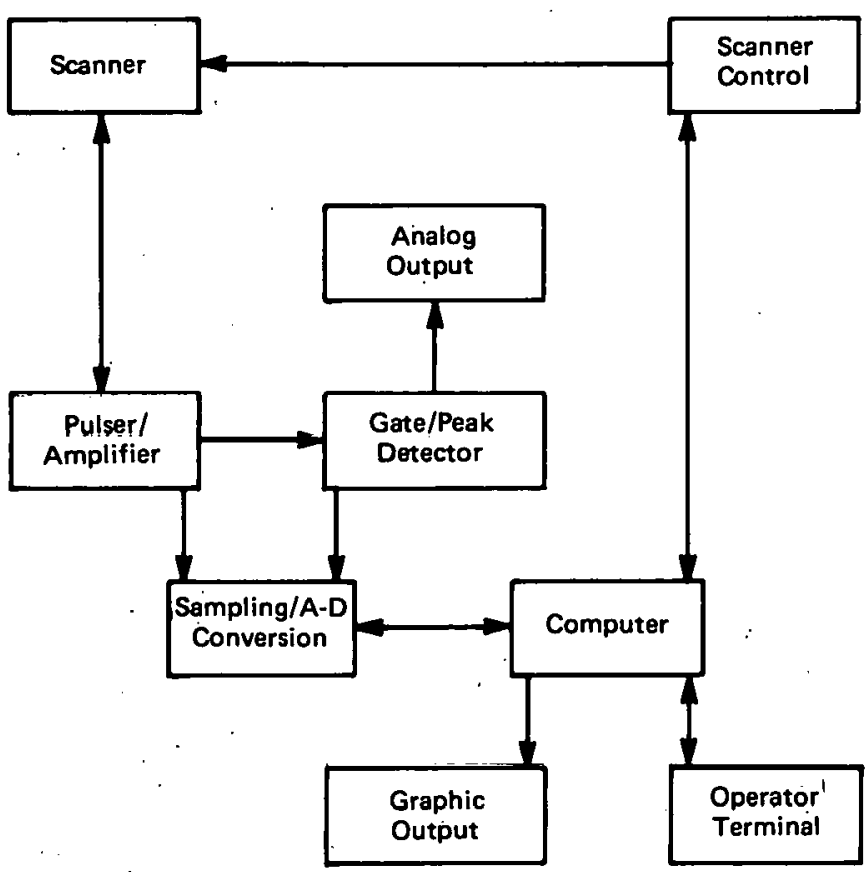

Figure 2 shows the improved system which controls test part scanning, waveform acquisition, and data analysis. In the new system, the motor controller moves the scanner under the command of the system computer. Interrupts provide the computer 


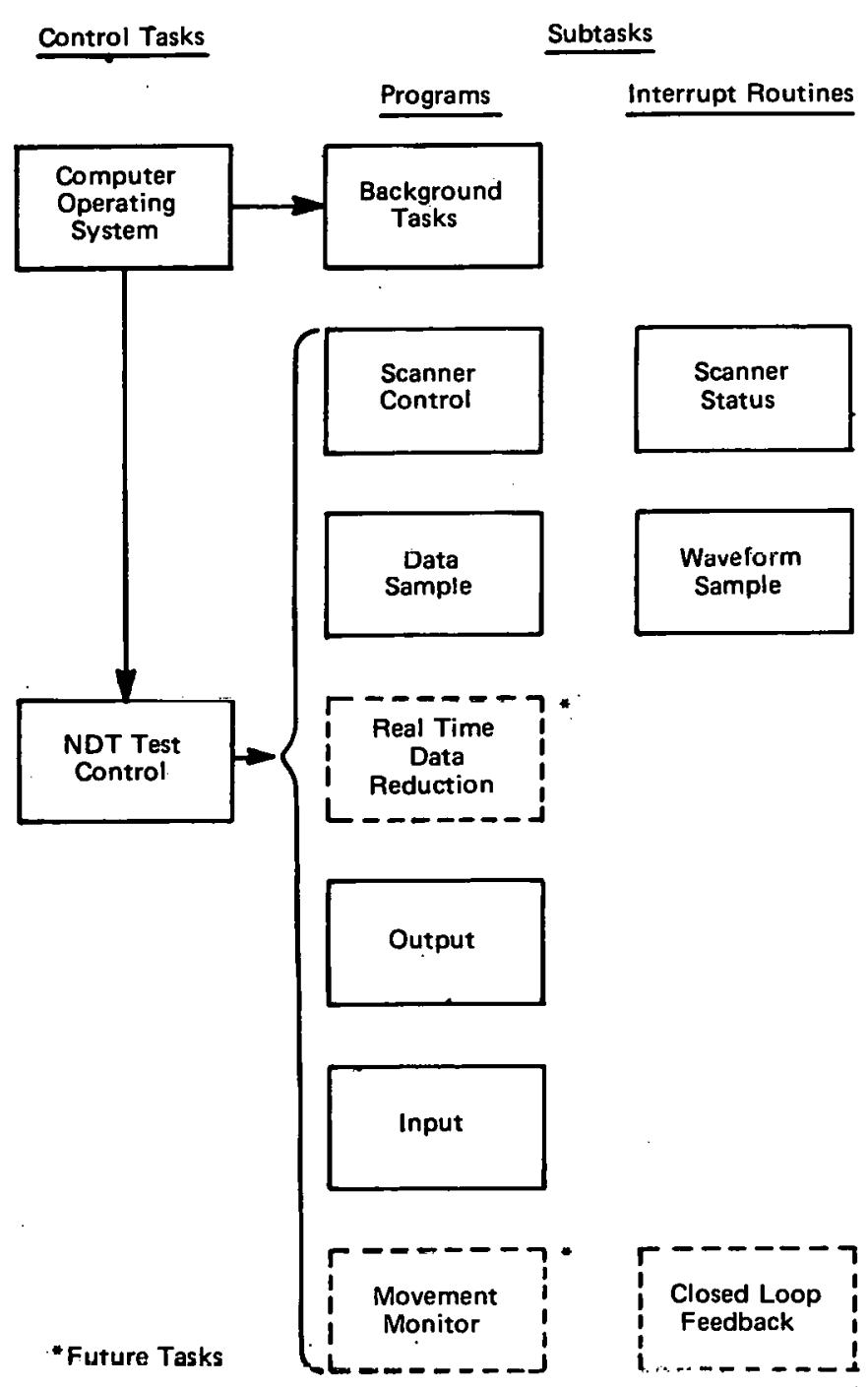

FIGURE 3. NDT Test Control Software

with the controller status. After completing a move, the data acquisition system can sample analog signals representing electronically measured waveform parameters, such as peak amplitude, or sample the entire pulse waveform from the pulse amplifiers. Sampled data can be recorded directly into computer storage devices or be processed in real time as the scan proceeds.

Scanning, data manipulation, input and output are controlled by a real time resident task which is part of the computer operating system, as shown in Figure 3. The operating system activates the test control program every 0.1 second. The control program determines which subtask is to be executed, executes the subtask, then deactivates itself, freeing the computer to continue with lower priority jobs. Intertask communication, work buffers, and subtask addressing are done through a common core area accessible to all tasks. Initial versions of the following subtasks have been completed.

1. A task to command the scanner motor control system and wait for the completion of a move.

2. A task to sample DC analog or waveform signals.

3. Tasks to output messages to the test operator or oulput data to storage devices.

4. Tasks to input responses from the test operator and input movement and data acquisition commands from computer storage devices.

The following subtasks will be added in the future:

1. Real time data analysis task as tests are : designed.

2. A task to monitor scanner movements to, check for errors and to protect the scanner and test parts.

\section{Ultrasonic Signal Waveform Parameters •}

\section{Initial Study of Parameters}

A study to determine effective waveform parameters to characterize the strength of bonded interfaces was performed by fabricating and analyzing a set of diffusion-bonded test samples. The test samples were cylindrical coupons composed of two 0.125 inch thick materials diffusion bonded as shown in Figure 4. The 0.375-inch diameter samples were electrochemically cored from 3-inch diameter bonded samples. Bond quality ranged from very poor to very good. Ultrasonic signals reflected from the diffusion-bonded interface and from the back surface were digitally recorded using a transient recorder having a sampling rate of 100 MHz. Longitudinal wave data were recorded using a single transducer at normal incidence, with a center frequency of approximately $17 \mathrm{MHz}$. Shear data were recorded using two transducers inclined 


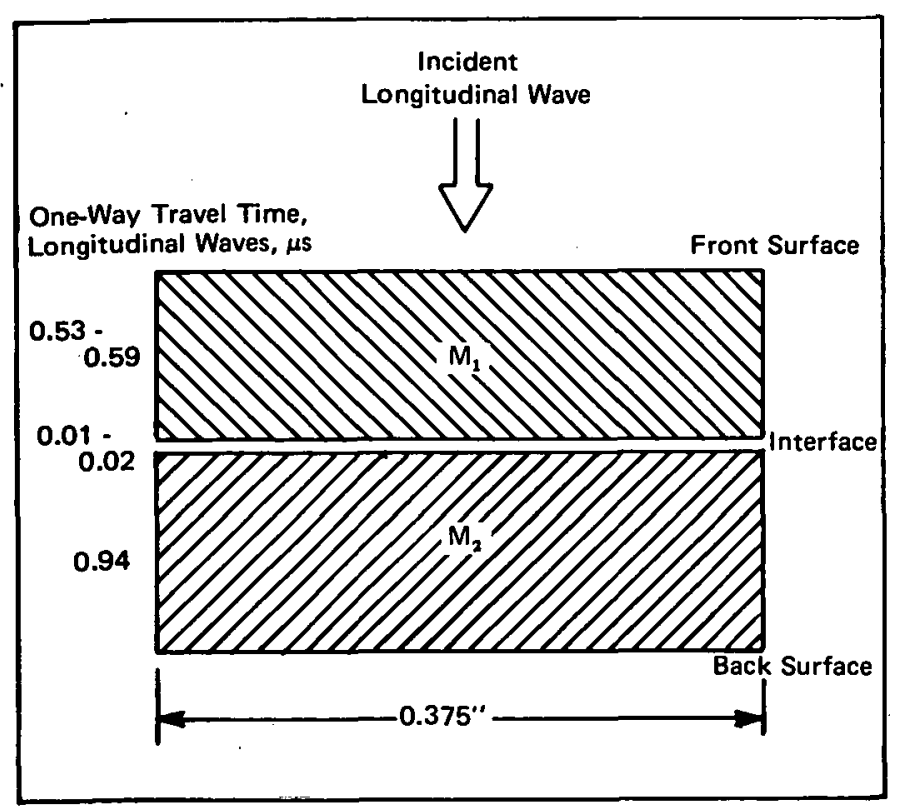

FIGURE 4. Configuration of Diffusion-Bond Sample

at the appropriate angles to excite a $40^{\circ}$ shear wave in the material. The base data consist of two sets of ultrasonic data recordings (normal L-wave and oblique S-wave) and one set of tensile test data.

Two distinct types of signals are present in the longitudinal data. Figure 5 shows a typical sample of each type. If the bond were poor, an increase in the acoustic impedance mismatch at the bond interface caused most of the energy to be reflected and reverberated within the top layer (period approximately $1.1 \mu \mathrm{s}$ ). A sound bond creates a closer impedance match at the bond interface which results in substantial energy reaching the bottom material back surface where it is reflected (round trip time $1.9 \mu \mathrm{s}$ ).

From the time plot of the longitudinal data, three regions are defined, as shown in Figure 6. The first region (Region $\mathrm{A}$ ) is the first signal component or the interface reflection. (The reflection from the front surface of the coupon was gated from the recorded signal package.) The second region (Region B) is the time interval of the first multiple reflection between the front surface and interface.
The third region (Region $\mathrm{C}$ ) is the second component or the back surface reflection of the pulse transmitted through the interface.

The analysis of relationships between waveform parameters and bond condition was done by Adaptronics, Inc., McLean, Virginia. Adaptronics defined a set of 54 features, seven of which proved significant. Four of these parameters were defined from the amplitude-time data (time domain parameters).

$$
\begin{aligned}
& X_{1}=\text { RMS Region B/RMS Region A } \\
& X_{2}=\text { RMS Region C/RMS Region A } \\
& X_{51}-\text { RMS Region D/Tütal RMS } \\
& X_{52}=\text { RMS Region C/Total RMS }
\end{aligned}
$$

The frequency domain parameters which proved significant in Adaptronics' models were defined from the variable $H(w)$, where $H(w)$ is the ratio (at each frequency in the Fourier transform) of the power spectrum of the entire three-region wavetrain divided by the transform of Region A.

$$
\begin{aligned}
& \mathrm{X}_{19}=\underbrace{1}_{\mathrm{H}_{\text {total }}} \sum_{\substack{\text { central } \\
\text { region }}} \mathrm{H}(\mathrm{w}) \\
& \mathrm{X}_{18}=\mathrm{H}_{\text {total }} \\
& \mathrm{X}_{11}=\text { such that } \sum_{\mathrm{i}=1}^{\mathrm{X}} \mathrm{H}\left(\mathrm{w}_{\mathrm{j}}\right) \geqslant 0.1 \mathrm{H}_{\text {total }}
\end{aligned}
$$

The values calculated by Adaptronics for these parameters versus measured tensile strength are given in Graphs 1 through 6, following the text of this report.

Adaptronics developed two models to characterize the bond strength data. The first model classified a bond as good or bad. The second model estimated the strength of good bonds. These models were developed using non-linear adaptive learning techniques and a set of time and frequency domain variables extracted from real ultrasonic measurements made on bonded samples having known bond strength. In the verification set for classification, there were 22 specimens of which 14 were bad bonds 

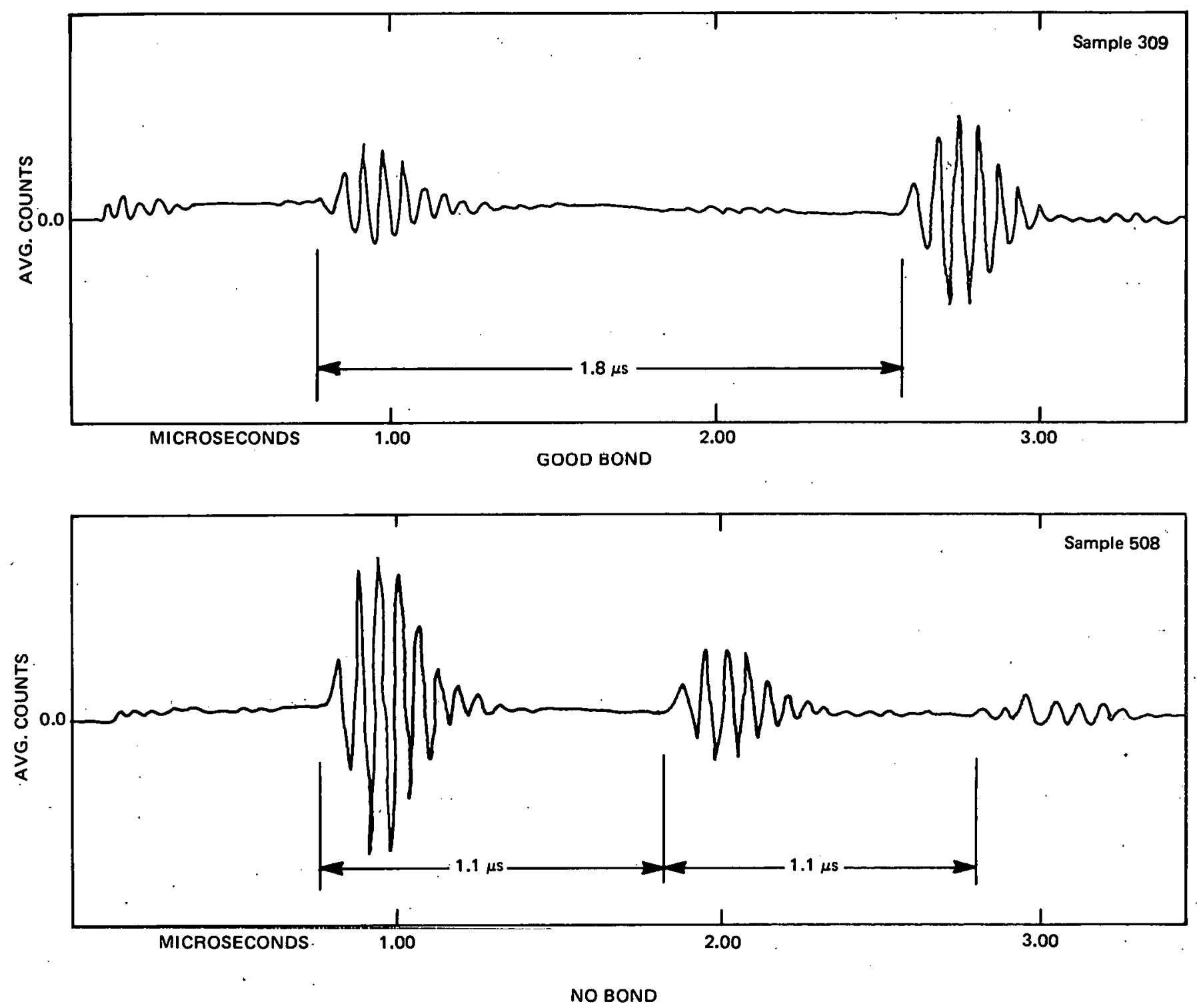

FIGURE 5. Typical Type I (Top) and Type II (Bottom) Waveforms

and 8 were good. Adaptronics' classification model classified $82 \%$ of these specimens correctly. The parameters calculated by Adaptronics and plotted in Graphs 1 through. 6 show none of the distinctive grouping characteristics considered necessary for bond classification, except for Graph 3. This one exception, for the variable $\mathrm{X}_{51}$, indicates that most of the good bonds are below $\mathrm{X}_{51}=0.47$, while most bad bonds are above the 0.47 level. No simple functional relationship is evident in
Adaptronics' data for good bonds. Although the relation between these variables and bond strength may depend on complex relationships derived with adaptive learning networks, analysis of graphs like those in Graphs 1 through 12, following the text of this report, can indicate the ability or inability of a given variable to classify a bond or predict its strength. Because of this lack of some definite trend, the model developed by Adaptronics does not provide reliable strength predictions. Validity 


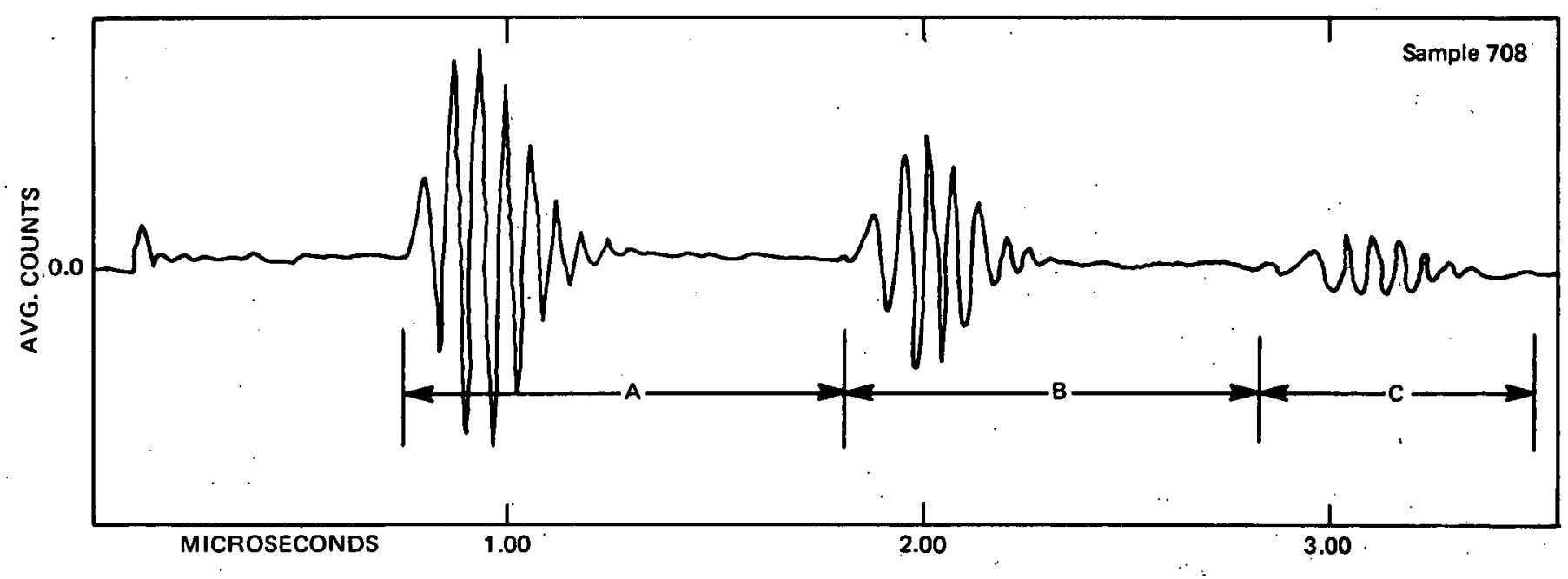

FIGURE 6. Definition of Pulse Rcgions

of the results from Adaptronics' prediction of actual bond strength or good bonds is suspect for the following three reasons:

1. The machining procedure used in preparing bond tensile coupons influenced the coupon strength.

2. The verification set for bond strength contained an insufficient number of well and partially bonded specimens to realistically evaluate the final bond strength prediction network.

3. One of the initial methods of parameter calculation introduced inconsistant data into the analysis.

\section{Improved Calculation of Waveform Parameters}

Parameter calculations made by Adaptronics have been modified to improve the ability of the significant waveform features to characterize diffusion bond strength. In recalculating the time domain variables, the following improvements were made:

1. The location of each region was allowed to vary so that the interface reflection, first multiple reflection, and back surface reflecction were completely contained within their respective time regions. Pulses overlapped the boundaries defined by Adaptronics (particularly, the backsurface reflection which tended to fall partially in Region B and partially in Region C) creating inconsistencies.

2. The second multiple reflection and backsurface reflection inherently overlap. Therefore, these two pulses were separated by theoretically calculating the second multiple reflection and subtracting it from the composite overlapped signal.

3. Adaptronics calculated the RMS of the data within each region. Since the regions varied between samples and RMS is a function of region width, some inconsistency was introduced in the variables. The following steps were taken to eliminate these problems:

(a) The width of the first interface reflection was defined.

(b) Delays to the first multiple reflection and backsurface reflection were calculated by cross-correlation of the pulses.

(c) Regions of width equal to the first interface reflection width were defined around the first multiple and backsurface reflection.

(d) Pulse energy was calculated for each of these regions for the reflection of interest. 
4. Two additional time domain variables were added using cross correlation peak heights $(\mathrm{CCPH})$.

$$
\begin{aligned}
& \mathrm{X}_{55}=\mathrm{CCPH} \text { Region } \mathrm{B} / \mathrm{CCPH} \text { Region A } \\
& \mathrm{X}_{56}=\mathrm{CCPH} \text { Region } \mathrm{C} / \mathrm{CCPH} \text { Region A }
\end{aligned}
$$

In reanalyzing the frequency domain variables, the following new variables showed significant improvement over the frequency parameters chosen by Adaptronics.

$$
\text { 1. } \begin{aligned}
\mathrm{X}_{57} & =\nabla \mathrm{E}_{\mathrm{c}} \text { Region } \mathrm{B} / \nabla \mathrm{E}_{\mathrm{c} \text { Region } \mathrm{A}} \\
\mathrm{X}_{58} & =\nabla \mathrm{E}_{\mathrm{c}} \text { Rcgion } \mathrm{C} / \nabla \mathrm{E}_{\mathrm{c} \text { Region A }} \\
\mathrm{X}_{59} & =\nabla \mathrm{E}_{\mathrm{C}} \text { Region } \mathrm{B} / \nabla \mathrm{E}_{\mathrm{c} \text { Region } \mathrm{C}}
\end{aligned}
$$

Where $\nabla E_{c}$ is the energy contained in the central frequency region of the Fourier transform of the pulse.

$$
\text { 2. } \begin{aligned}
\mathrm{X}_{60} & =\mathrm{E}_{2} \text { Region } \mathrm{B} / \mathrm{E}_{2} \text { Region } \mathrm{A} \\
\mathrm{X}_{61} & =\mathrm{E}_{2} \text { Region } \mathrm{C} / \mathrm{E}_{2} \text { Region } \mathrm{A} \\
\mathrm{X}_{62} & =\mathrm{E}_{2} \text { Region } \mathrm{B} / \mathrm{E}_{2} \text { Region } \mathrm{C}
\end{aligned}
$$

Where $E_{2}=\sum_{i=1}^{E_{c}}(i)^{2} E_{j}$ is the cumulative second moment of the energy spectrum from the beginning to the center peak of the energy spectrum.

$$
\text { 3. } \begin{aligned}
& \mathrm{X}_{63}=\text { Deconvolution Region } \mathrm{B} \text { by Region } \mathrm{A} \\
& \mathrm{X}_{64}=\text { Deconvolution Region } \mathrm{A} \text { by Region } \mathrm{C} \\
& \mathrm{X}_{65}=\text { Deconvolution Region } \mathrm{B} \text { by Region } \mathrm{C}
\end{aligned}
$$

Where the deconvolution is done only across the central region of the complex spectrum of each pulse region.

Examples of the recalculated values for these parameters from bond test data versus measured tensile strength are given in Graphs 7 through 12 . The recalculated parameters show improved separation of data into the kind of grouping necessary for bond classification. However, like Adaptronics' calculated data, no simple functional relationship is evident in the data for good bonds.

\section{FUTURE WORK}

Development of additional waveform parameters designed to better differentiate bond strength is in progress. Features obtainable with higher frequency; broad bandwidth longitudinal and transverse ultrasonic pulses are being considered. These additional parameters are needed to more closely analyze the case of in-contact but non-bonded surfaces, to identify the character of the observed two groups of non-bonded sample data, and to improve the ability to distinguish bonded and non-bonded areas. Future experiments to provide a larger data base and develop additional signal processing and feature extraction variables may be performed.

For diffusion bonded or brazed parts with differences in material and geometry from the test coupons discussed in the previous section, some of the features used to define bond strength groups do not apply, while some indicate relationships but give no absolute measure of bond condition. For example, interface reflections from brazed parts behave like reflections from the test coupon interfaces but the range of parameter values for good bonds is different. Figure 7 shows the grouping of values of the reflected interface energy from scans of two brazed parts with known areas of poor bonding. The figure plots the number of scan points which have a particular reflected pulse energy versus reflected pulse energy (pulse energy leaving the transducer was constant). The figure shows three groups of points similar to the grouping of parameter values for the test coupon data. The tight group at the left is from bonded areas, the middle group from non-bonded areas with the interface surfaces in close contact, and the right group from non-bonded areas with large impedance mismatches. Work is in progress to determine parameter values (from standards or test specimens identical to actual parts) which define bond strength for production parts.

\section{CONCLUSIONS}

1. The current method of ultrasonic testing of touch braze interfaces does not lend itself to 


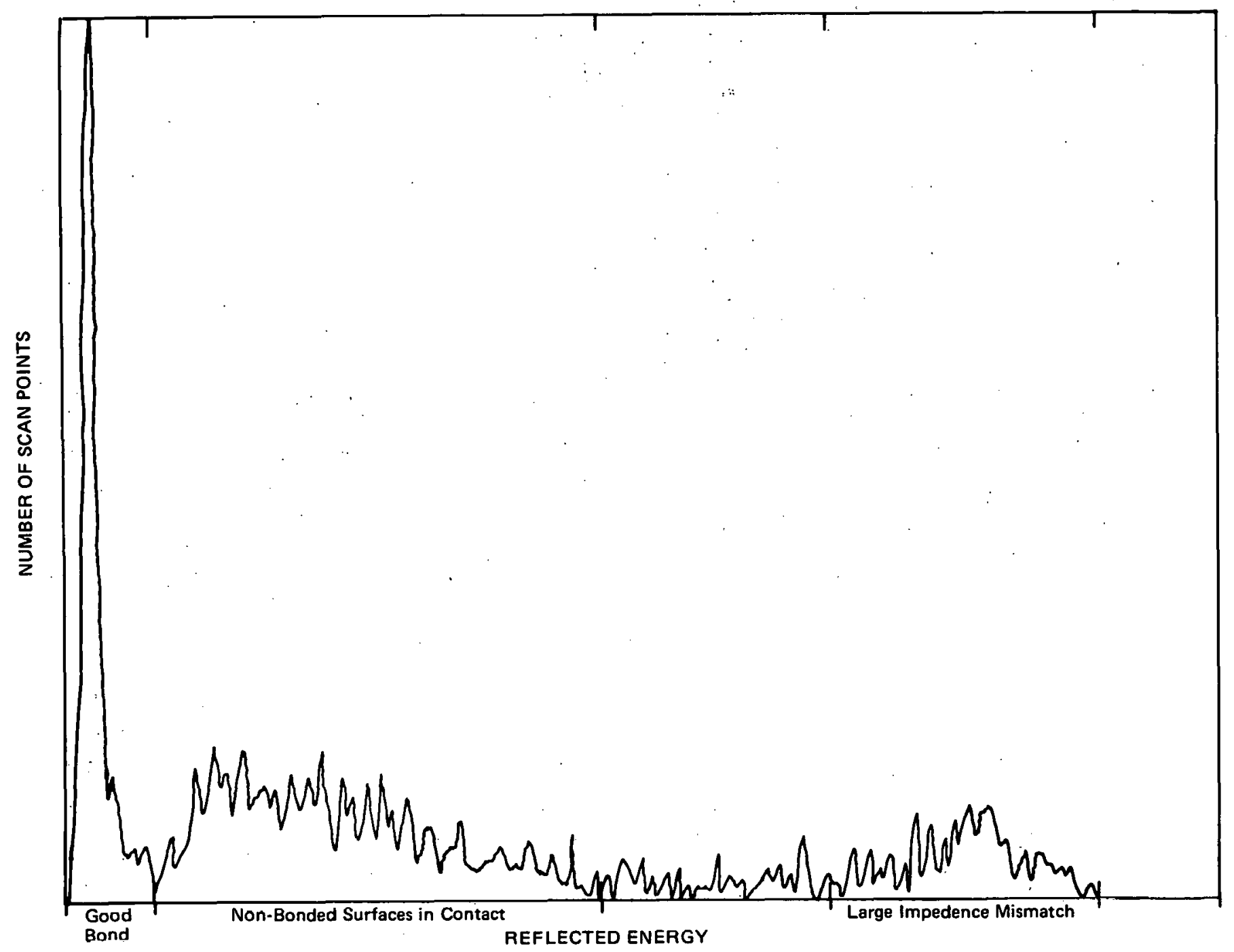

FIGURE 7. Distribution of Scan Points of Energy Reflected From Diffusion Bonded Interfaces

more refined analysis of reflected ultrasonic information which requires sampling the entire waveform signal.

2. A development version of an improved computer-controlled, automated scanning, data acquisition and data analysis system is complete. The system performs on-line capture, storage and analysis of entire waveform signals by the control computer.

3. The results of an initial effort to determine effective ultrasonic waveform parameters to characterize the strength of diffusion or eutectic bonds performed by Adaptronics were not ready for production use.

4. Waveform parameter calculation methods from the initial study were improved and incorporated into a second evaluation of data used in the initial effort. The recalculated parameters show improved separation and grouping of data . necessary for bond classification but still lack a simple functional relationship.

5. Further studies to develop additional waveform parameters to better distinguish bond strength and to apply these parameters to actual NDT tests are needed and have begun. 


\section{G R A P H S}

(1 through 12)

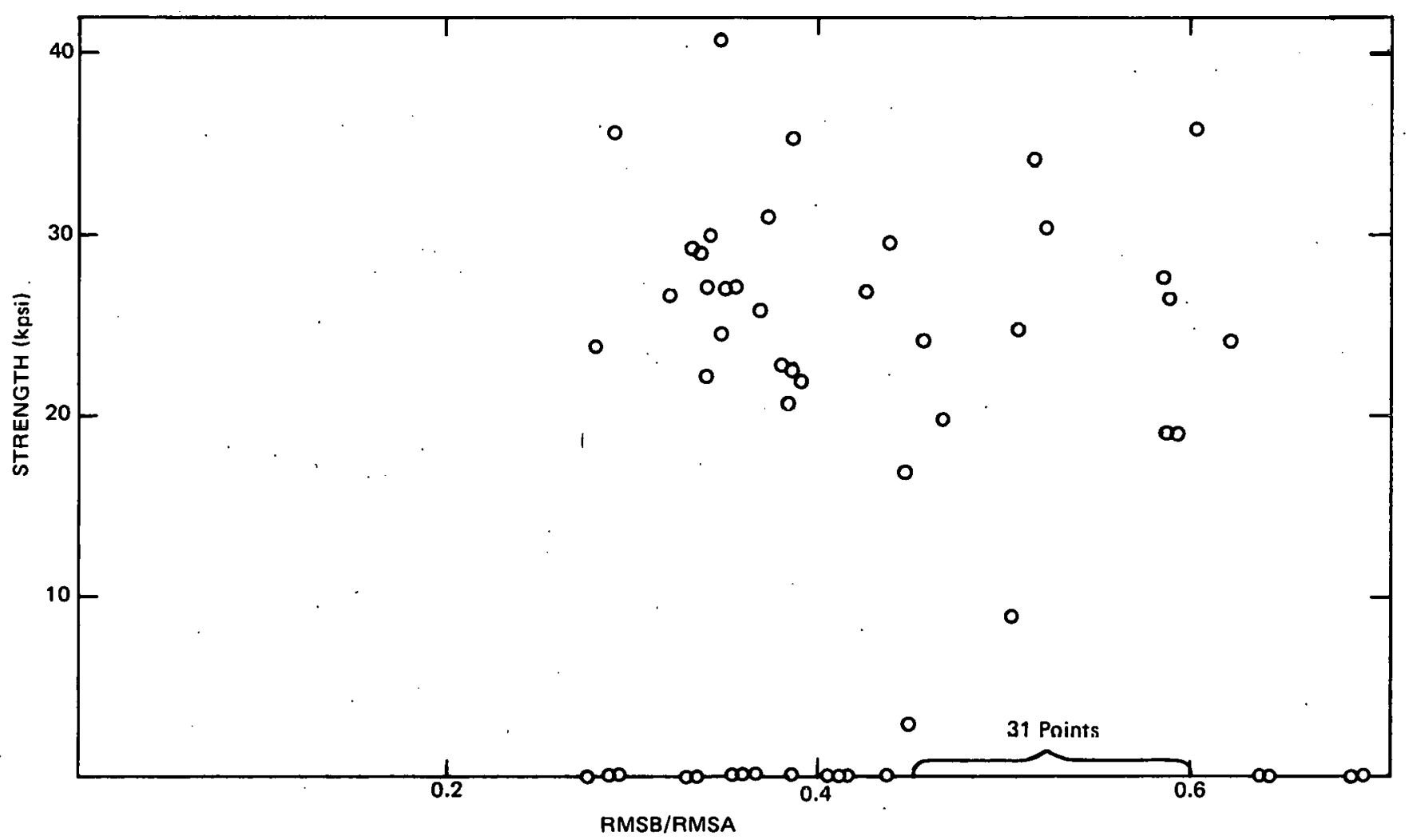

GRAPH 1. Measured Sample Tensile Strength as a Function of $X_{1}=$ RMS Region B/RMS Region $A$ Calculated by Adaptronics 


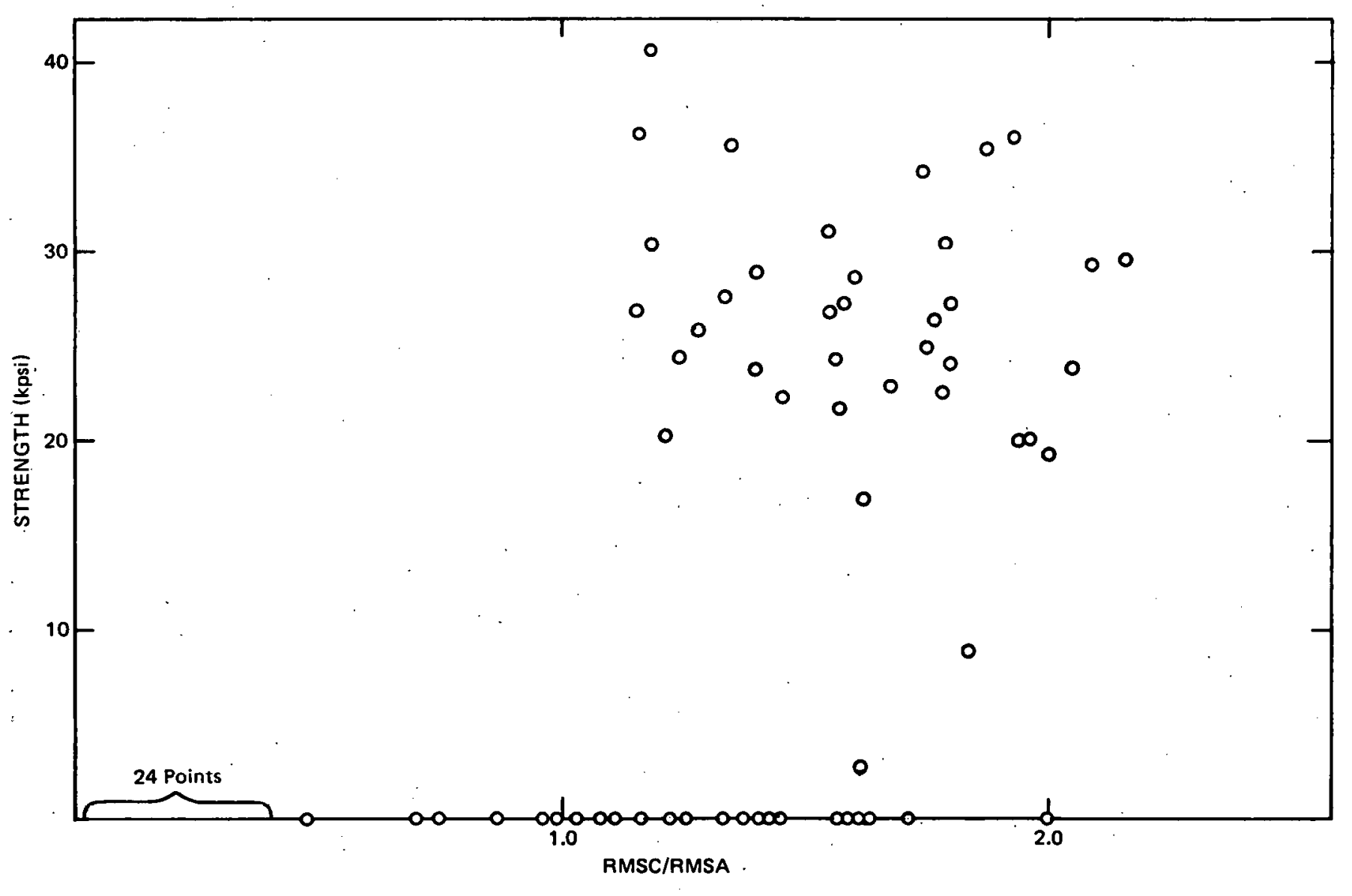

GRAPH 2. Measured Sample Tensile Strength as a Function of $\mathrm{X}_{2}=\mathrm{RMS}$ Region C/RMS Region A Calculated by Adaptronics 


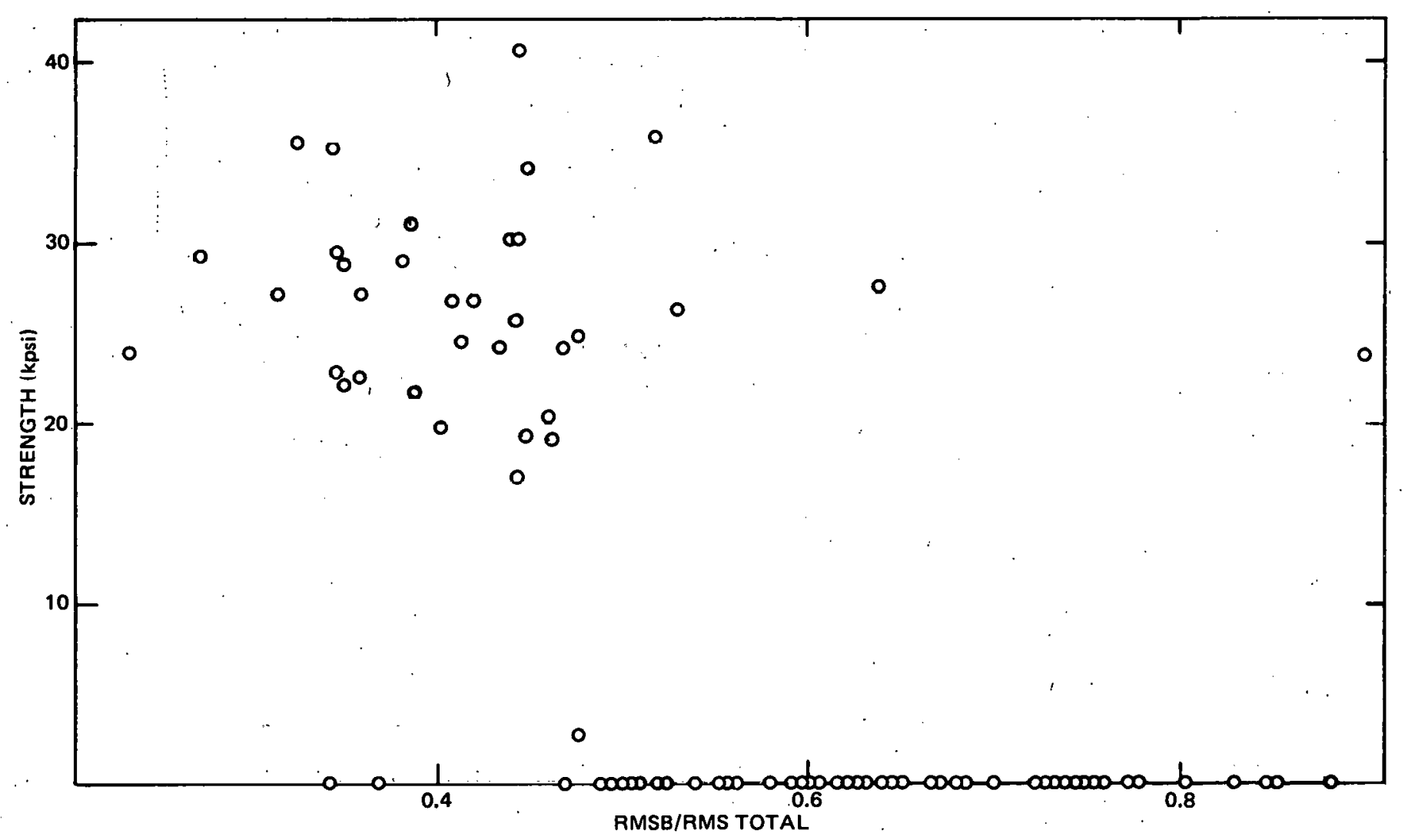

GRAPH 3. Measured Sample Tensile Strength as a Function of $X_{51}=$ RMS Region $B /$ RMS Total Calculated by Adaptronics 


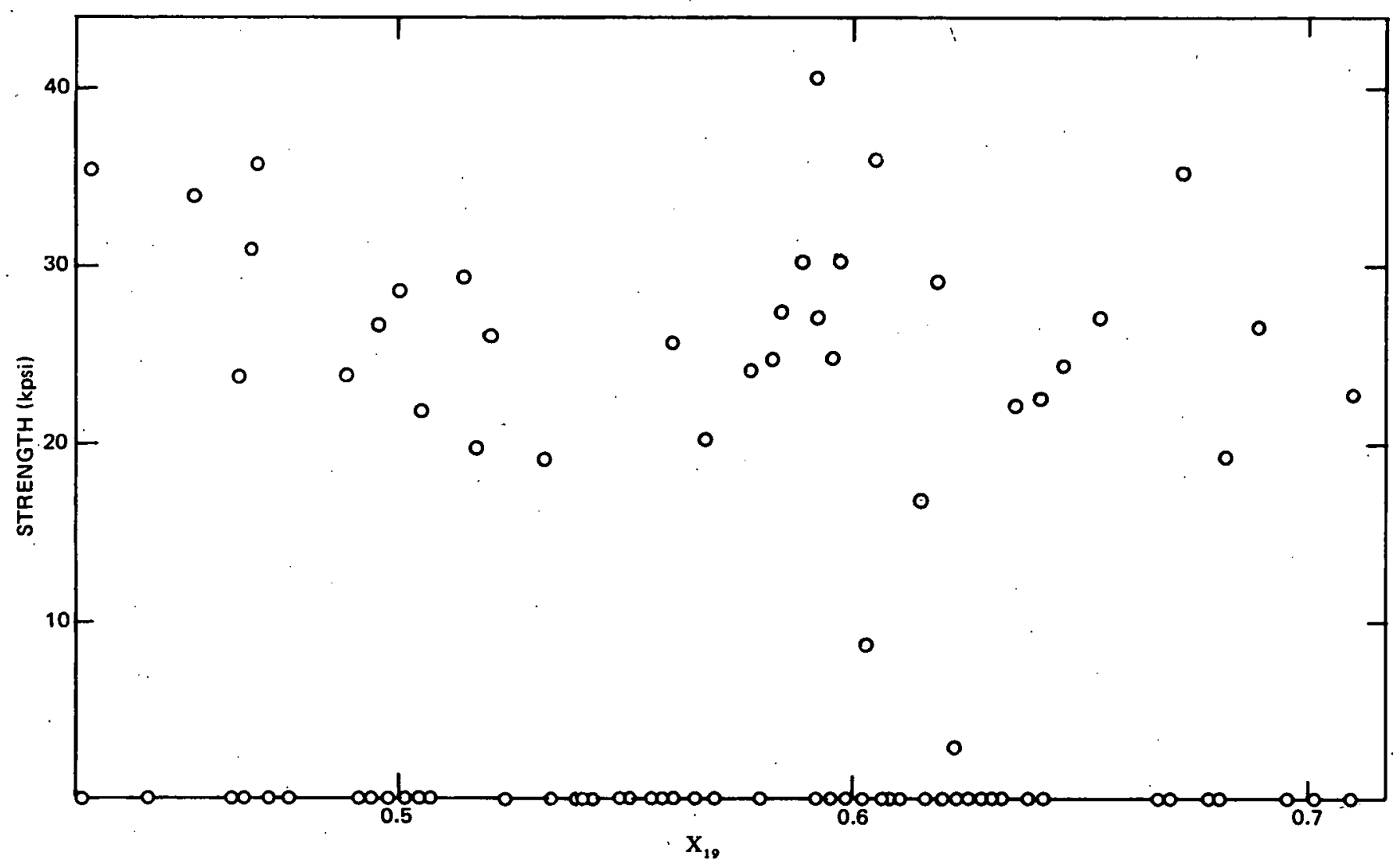

GRAPH 4. Measured Sample Tensile Strength as a Function of $X_{19}=\frac{1}{H_{\text {total }}} \underset{\begin{array}{c}\text { central } \\ \text { region }\end{array}}{\Sigma} H(w)$ Calculated by Adaptronics 


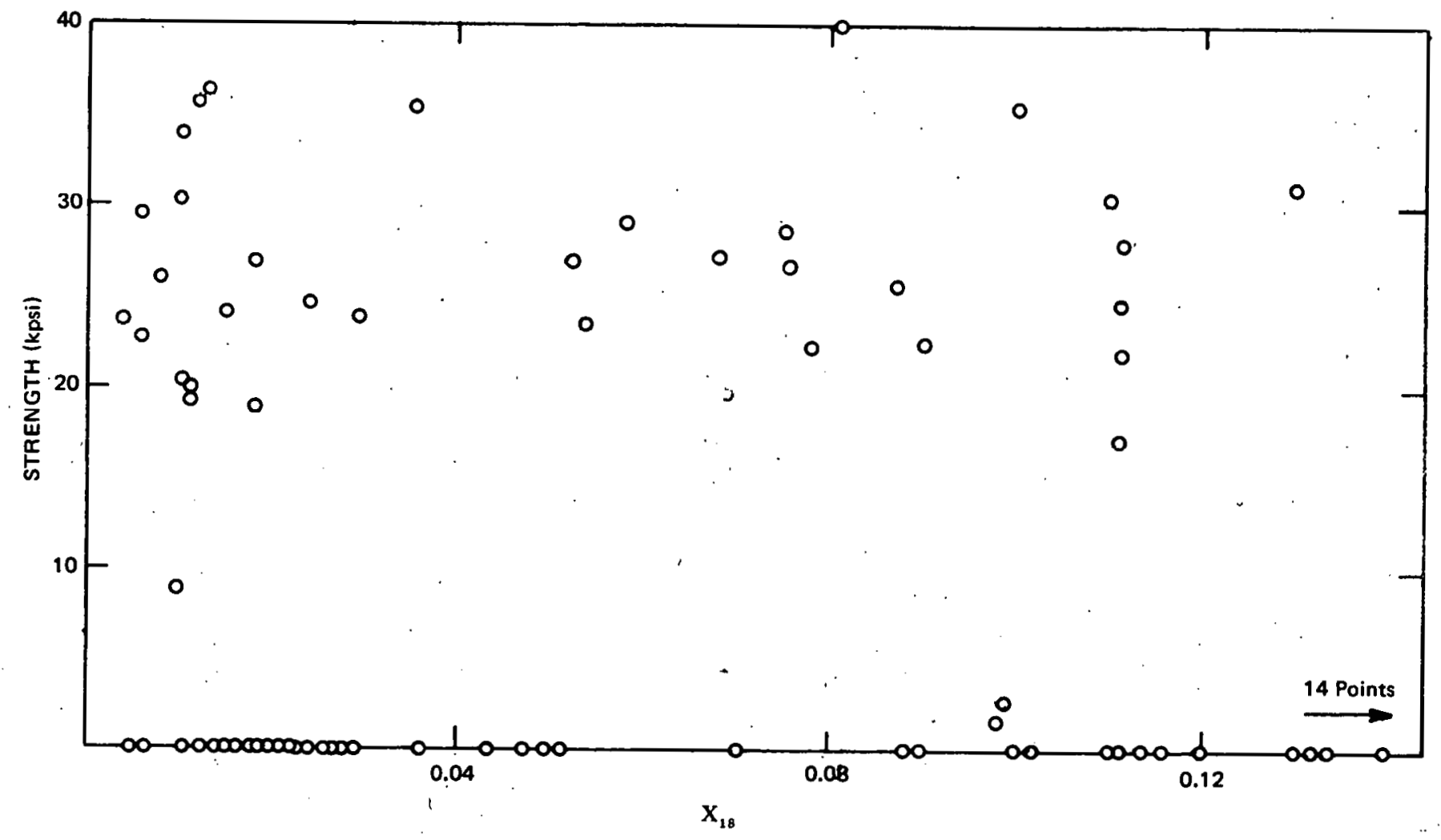

GRAPH 5. Measured Sample Tensile Strength as a Function of $\mathrm{X}_{18}=\mathrm{H}_{\text {total }}$ Calculated by Adaptronics 


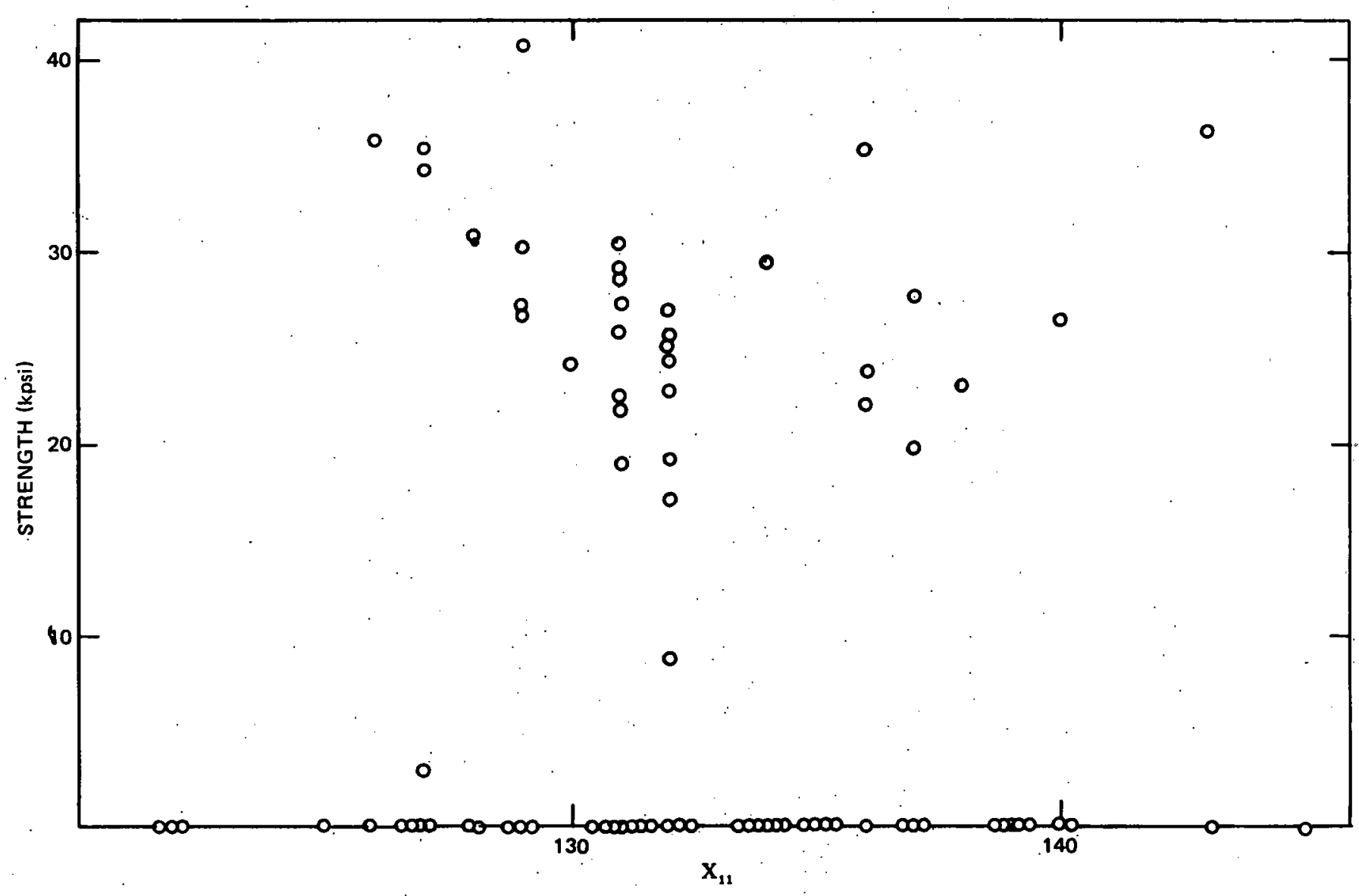

GRAPH 6. Measured Sample Tensile Strength as a Function of $\mathrm{X}_{11}=\mathrm{X}$ Such That $\sum_{\mathrm{i}=1}^{X} \mathrm{H}(\mathrm{w}) \geqslant 0.1 \mathrm{H}_{\text {total }}$ Calculated by Adaptronics 


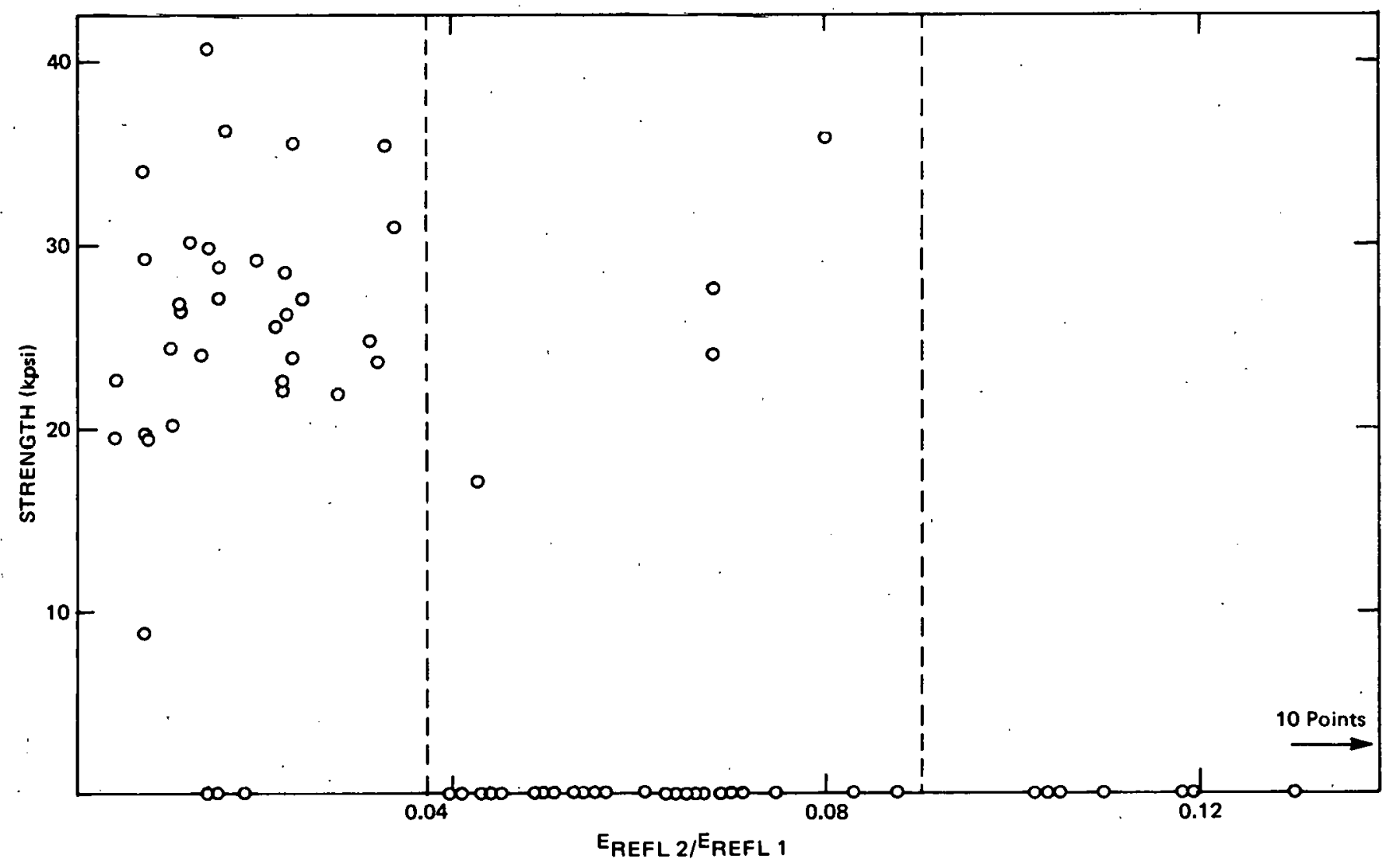

GRAPH 7. Measured Sample. Tensile Strength as a Function of $X_{1}=$ Energy Region B/Energy Region A Recalculated Data 


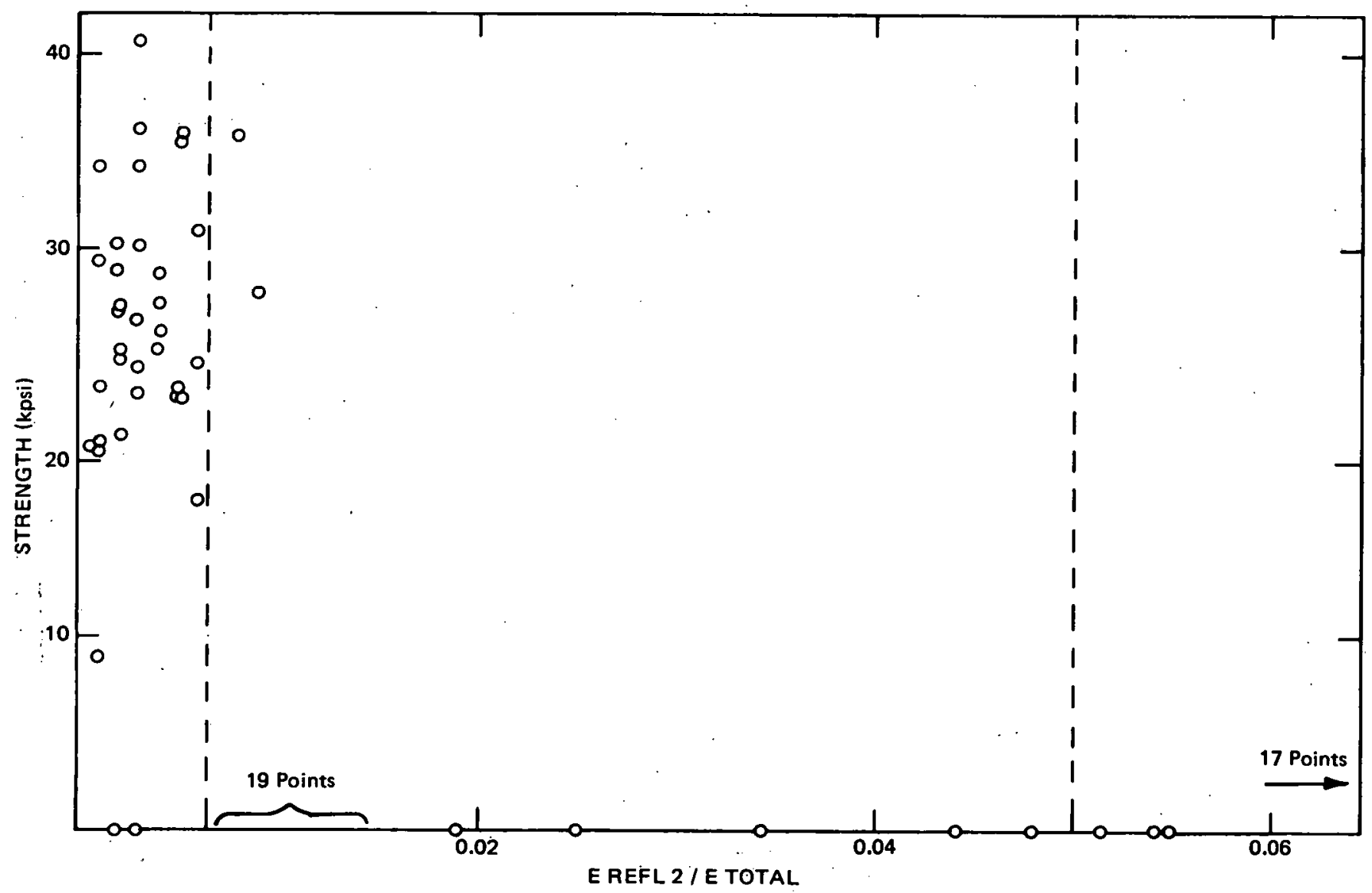

GRAPH 8. Measured Sample Tensile Strength as a Function of $\mathbf{X}_{51}=$ Energy Region B/ Total Energy ${ }^{\text {Recalculated Data }}$ 


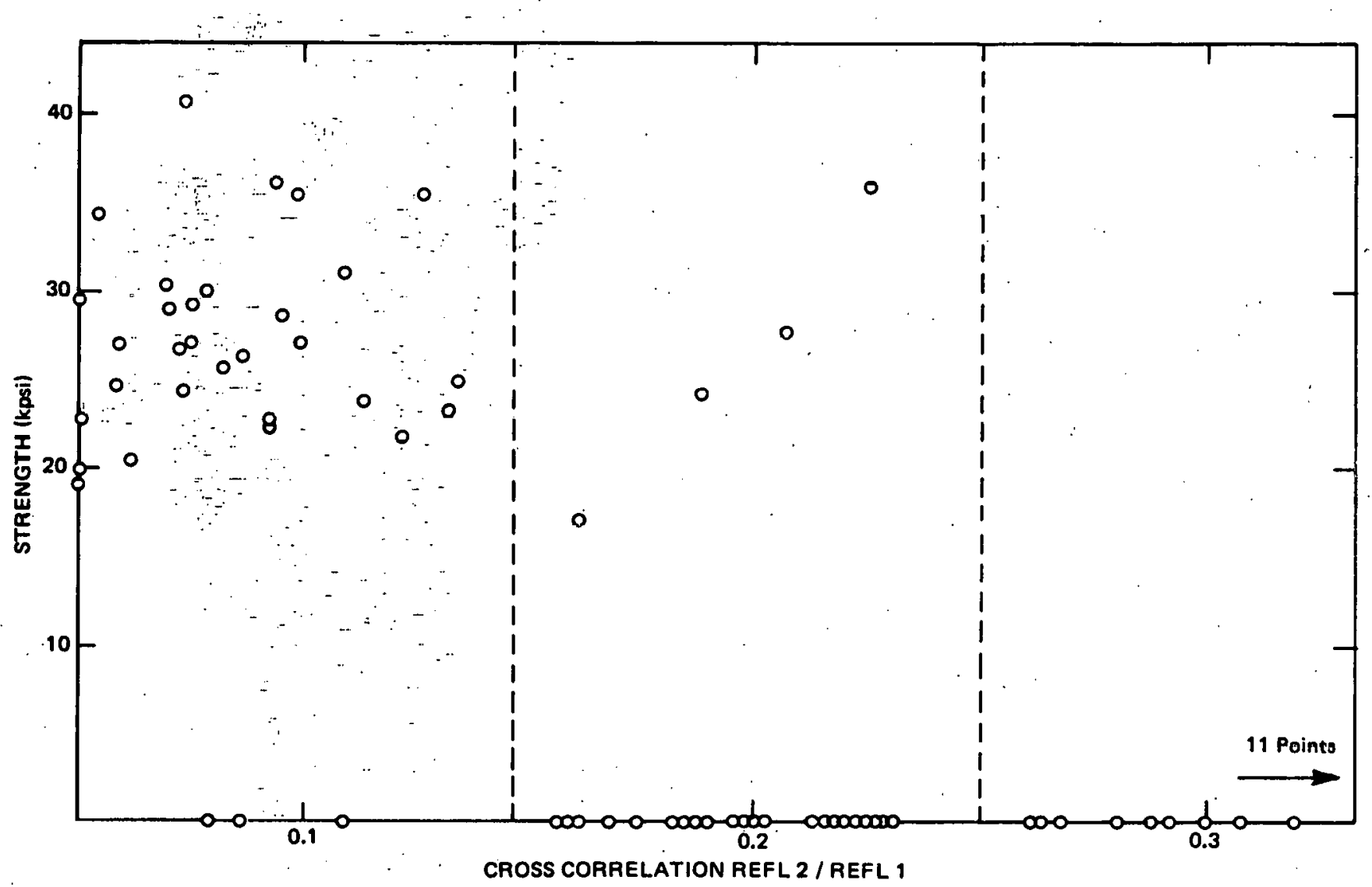

GRAPH 9. Measured Sample Tensile Strength as a Function of $X_{56}=$ First Multiple Reflection Cross-Correlation Peak/Interface Reflection Peak-Recalculated Data 


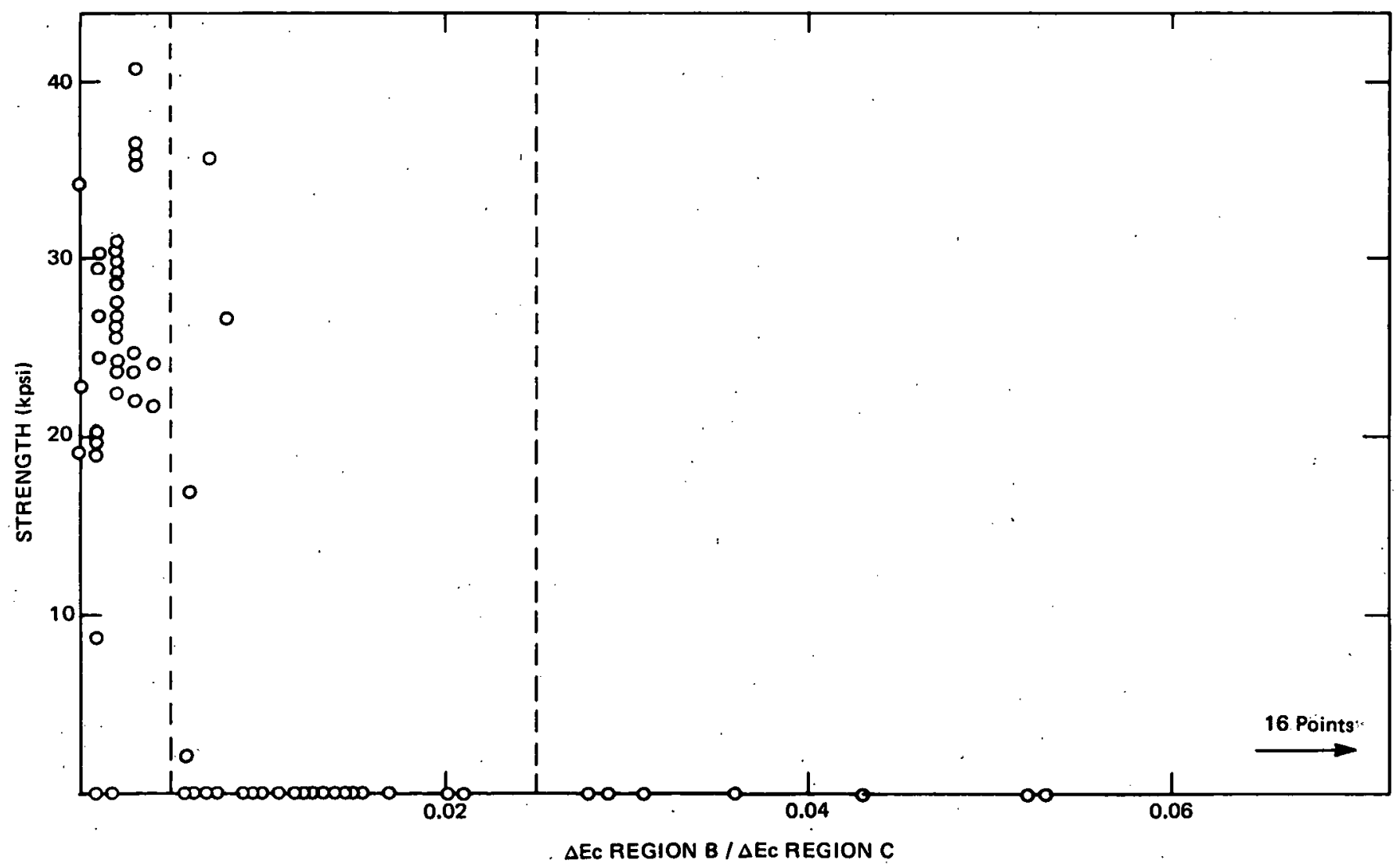

GRAPH 10. Measured Sample Tensile Strength as a Function of $\mathrm{X}_{59}=\Delta \mathrm{Ec}$ Region $\mathrm{B} / \Delta \mathrm{Ec}$ Region $\mathrm{C}$ Recalculated Data 


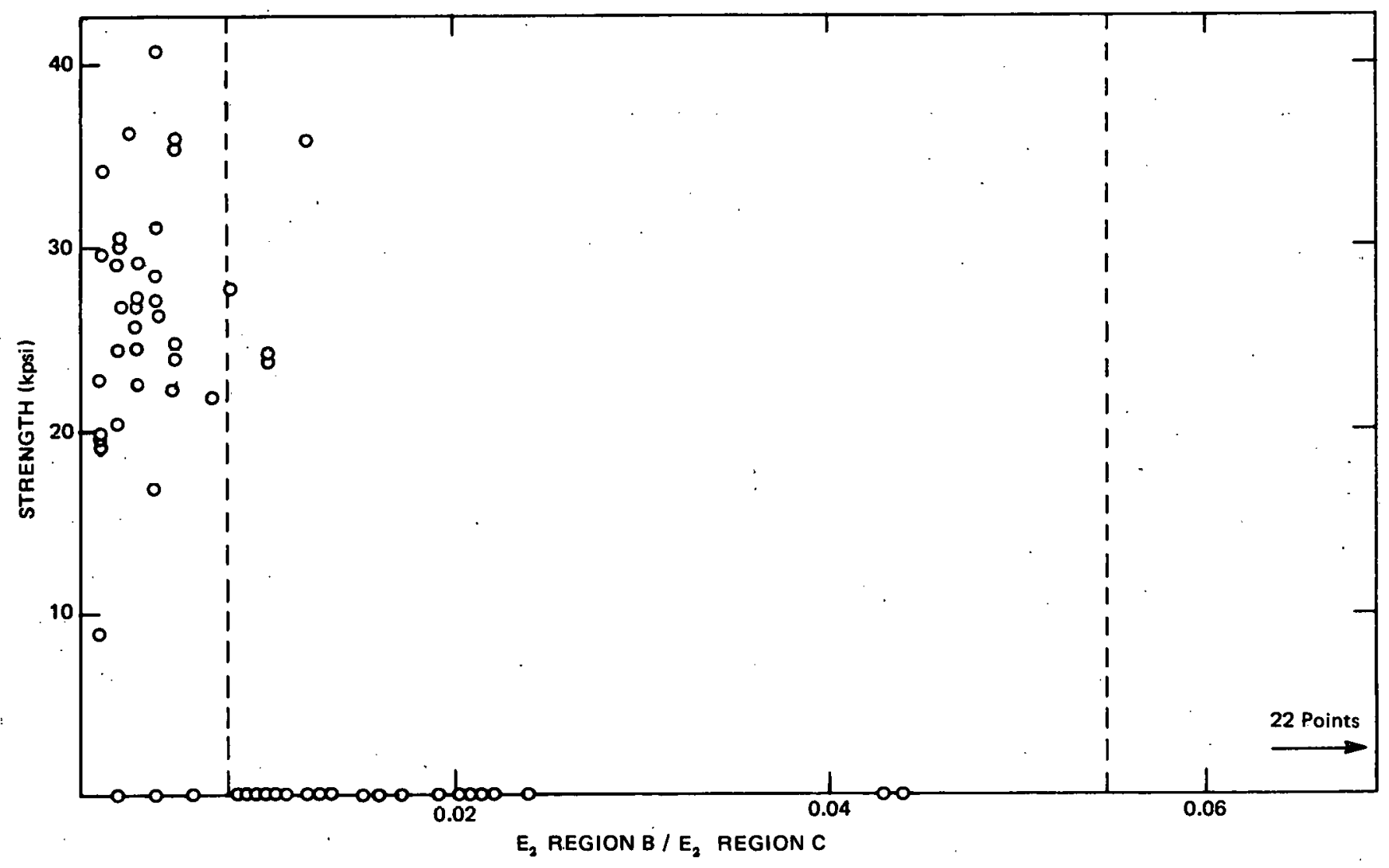

GRAPH 11. Measured Sample Tensile Strength as a Function of $X_{62}=E_{2}$ Region $B / E_{2}$ Region C Recalculated Data 


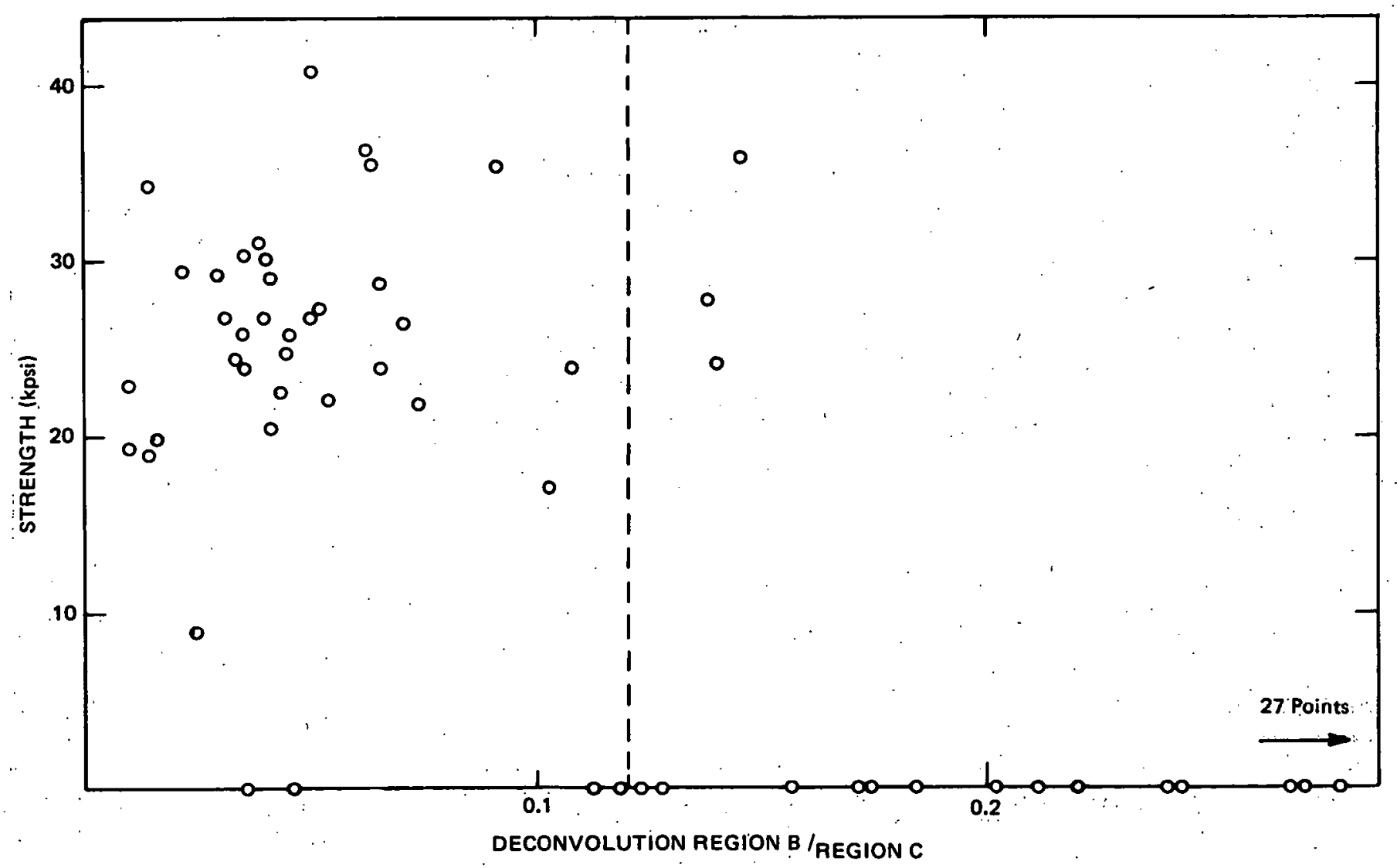

GRAPH 12. Measured Sample Tensile Strength as a Function of $\mathrm{X}_{65}=$ Deconvolution of Region B by Region C - Recalculated Data 